\title{
MPDB 2.0: a large scale and integrated medicinal plant database of Bangladesh
}

\author{
Nazmul Hussain ${ }^{1}$, Rony Chanda', Ruhshan Ahmed Abir², Mohsina Akter Mou ${ }^{3}$, Md. Kamrul Hasan ${ }^{1 *}$ and \\ M. Arif Ashraf ${ }^{4^{*}}$ (D)
}

\begin{abstract}
Objective: MPDB 2.0 is built to be the continuation of MPDB 1.0, to serve as a more comprehensive data repertoire for Bangladeshi medicinal plants, and to provide a user-friendly interface for researchers, health practitioners, drug developers, and students who wish to study the various medicinal \& nutritive plants scattered around Bangladesh and the underlying phytochemicals contributing to their efficacy in Bangladeshi folk medicine.

Results: MPDB 2.0 database (https://www.medicinalplantbd.com/) comprises a collection of more than five hundred Bangladeshi medicinal plants, alongside a record of their corresponding scientific, family, and local names together with their utilized parts, information regarding ailments, active compounds, and PubMed ID of related publications. While medicinal plants are not limited to the borders of any country, Bangladesh and its Southeast Asian neighbors do boast a huge collection of potent medicinal plants with considerable folk-medicinal history compared to most other countries in the world. Development of MPDB 2.0 has been highly focused upon human diseases, albeit many of the plants indexed here can serve in developing biofuel (e.g.: Jatropha curcas used in biofuel) or bioremediation technologies (e.g.: Amaranthus cruentus helps to reduce cadmium level in soil) or nutritive diets (Terminalia chebula can be used in nutritive diets) or cosmetics (Aloe vera used in cosmetics), etc.
\end{abstract}

Keywords: MPDB2.0, Medicinal plant, Medicinal plant database of Bangladesh, Folk medicine

\section{Introduction}

Since ancient times nature has always provided its favoured children (humans) with both remedies for fighting diseases and nutrition products to maintain good health via plants full of potent medicinal properties and nutritive values, [1] and our forefathers have utilized this boon from mother nature to the fullest, a sign of which can be still found in the local folk medicinal therapies [24]. While our predecessors hardly understood the underlying mechanisms and chemical mediators responsible

\footnotetext{
*Correspondence: kamrulhasanhridoy205@gmail.com; mohammadarif@umass.edu

${ }^{1}$ Department of Biochemistry and Molecular Biology, Tejgaon College, National University of Bangladesh, Gazipur 1704, Bangladesh

${ }^{4}$ Biology department, University of Massachusetts Amherst, Amherst, MA, USA

Full list of author information is available at the end of the article
}

for the efficacy of these plants, recent advancement in technology (which includes techniques, instrumentation, and automation in isolation and structural characterization) allows us to learn the underlying mechanisms of these herbal treatments in depth $[5,6]$ and discover the full potential for the usage of these plants full of potent medicinal properties and nutritive values $[7,8]$.

Several studies in recent times have suggested that plant active compounds or secondary metabolites possess immense potential for application in both research and clinical industries, for instance in developing nutraceuticals, nutrition products, biofuel technology, insecticides, flavouring agents, colouring agents, smelling agents, or fragrance, etc. [9-13]. According to records approximately 4,20,000 plant species are existing in nature among which about 10,000 to 15,000 plants have been studied for their medicinal and nutritional 
properties and about 200 of these plants or their active compounds have been adopted in western medicines [14, 15]. While natural substances are no longer used in modern medicinal therapies since the early decades of the last century, studies on bioactive molecules originating from plants continue to play a vital role in the development of novel medicinal therapies for emerging new diseases [16-18] as the parallel advancement of both biology and technology opens up an inexhaustible repertoire of naturally occurring compounds that have the potential to lead to the development of efficient and novel treatment strategies for diseases, both old and new $[1,7,15]$.

MPDB 2.0 database (plants of 122 family, 381 genus and 557 species), like MPDB 1.0 [19] is a user-friendly interface committed to rendering information (including their scientific names, family names, local names, utilized parts, related ailments, and active compounds) of plants around Bangladesh which have been suggested to have potent medicinal and/or nutritive properties, for both national and international researchers, health practitioners, drug developers and students who wish to study the medicinal and nutritional plants of
Table 1 Major plant families in the MPDB2.0

\begin{tabular}{lll}
\hline Family & No of entries & \% of each families \\
\hline Amaranthaceae & 10 & 1.795332 \\
Apocynaceae & 13 & 2.333932 \\
Araceae & 14 & 2.513465 \\
Asteraceae & 25 & 4.48833 \\
Convolvulaceae & 11 & 1.974865 \\
Cyperaceae & 11 & 1.974865 \\
Euphorbiaceae & 28 & 5.02693 \\
Fabaceae & 50 & 8.976661 \\
Lamiaceae & 31 & 5.56553 \\
Lauraceae & 11 & 1.974865 \\
Malvaceae & 13 & 2.333932 \\
Poaceae & 21 & 3.770197 \\
Rubiaceae & 11 & 1.974865 \\
Rutaceae & 11 & 1.974865 \\
Solanaceae & 19 & 3.411131 \\
Other & 278 & 49.91023 \\
Total & 557 & 100 \\
\hline
\end{tabular}
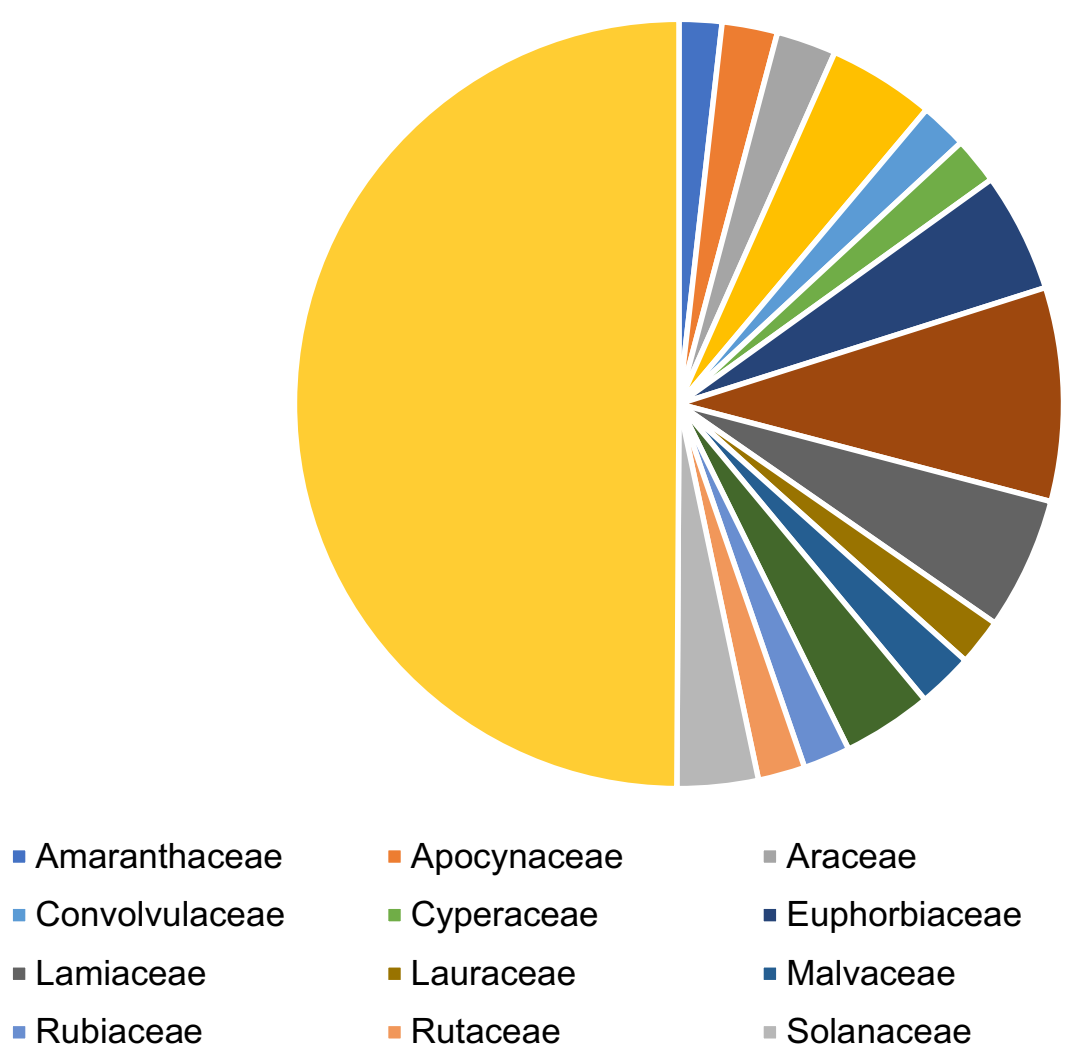

\section{Asteraceae \\ - Fabaceae \\ - Poaceae \\ - Other}

Fig. 1 Pie chart demonstrates the most prominent plant families, expressed as percentage, from the MPDB 2.0. Families contain 10 or more than 10 plants are represented here individually, and all other families were listed as "other" category. Details numbers are provided in the Table 1 


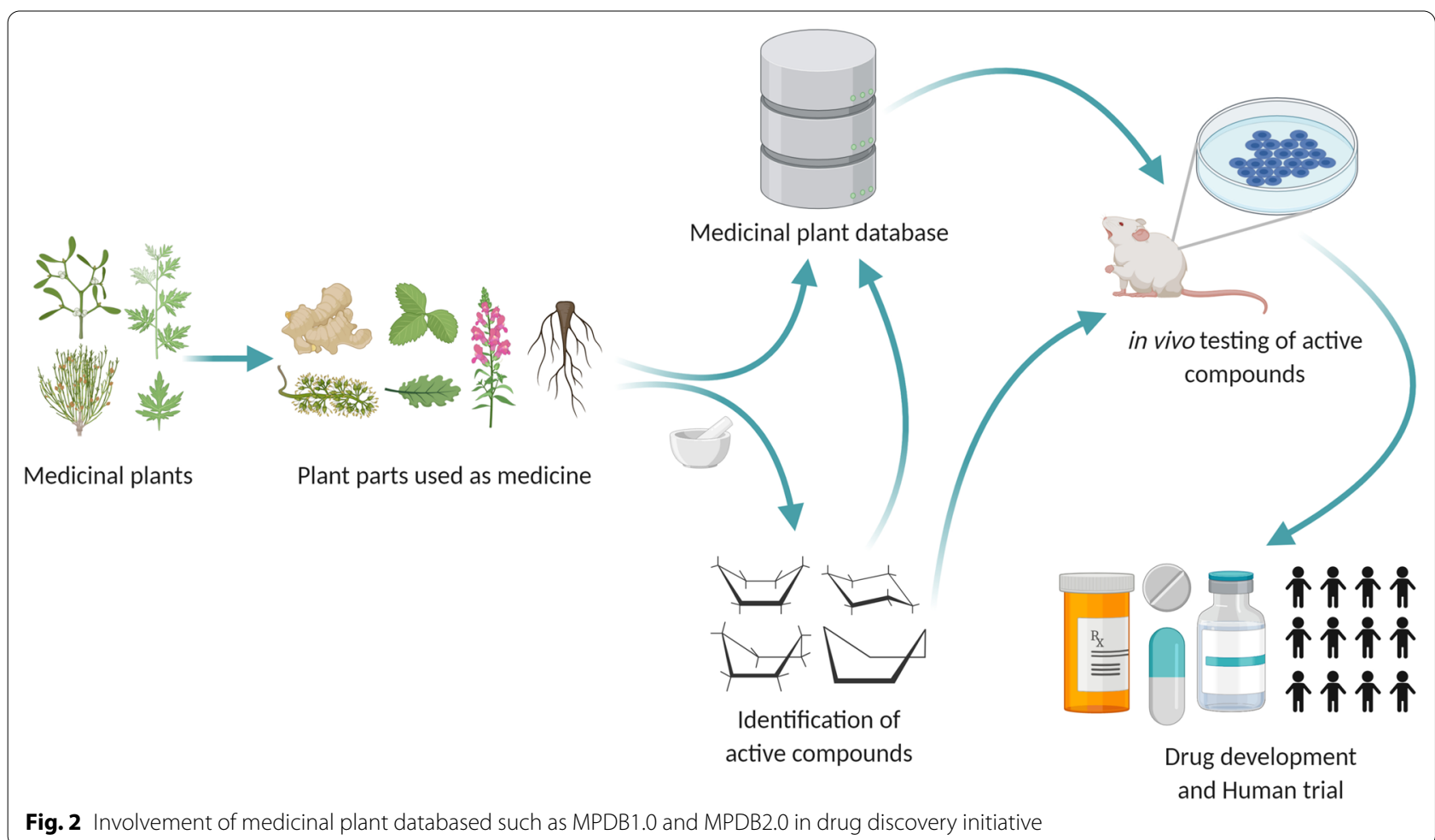

Bangladesh. Interestingly, we have found that certain families are more prominent and appeared in a higher frequency in the collection of medicinal plant, MPDB 2.0. For instance, Asteraceae, Euphorbiaceae, Fabaceae, Lamiaceae, Poaceae, Solanaceae families are major source of medicinal plants in our database (Fig. 1; Table 1). To help the scientific community in advancing biological sciences the authors have dedicated the MPDB 2.0 database to be an open-source server. An updated medicinal plant database will enhance the scientific community to advance in the field of drug discovery (Fig. 2). In addition, we have created a promotional animated video (https://www.youtube.com/ watch?v=tibx8MA6-Xs) for the MPDB 2.0 to reach wider audience and researchers.

\section{Main text \\ Methods and materials Literature mining}

To collect the necessary plant data for the MPDB 2.0 database, a cluster of 43 literatures retaining information regarding medicinal and nutritive values along with respective folk therapies of Bangladeshi medicinal plants corresponded by both national and international research groups have been studied. The scientific names, family names, local names, utilized parts, and active compounds or secondary metabolites of the related plants have been included in the search parameters. To identify synonymous plant scientific names and reduce redundancies, The Plant List web server (http://www.theplantlist.org/) has been utilized.

\section{Active compounds}

For assembling literature retaining information of active compounds of the indexed Bangladeshi medicinal plants a separate search was conducted by two researchers independently and the PubMed web server (https://pubmed. ncbi.nlm.nih.gov/) has been exclusively utilized for this. The scientific names and scientific name synonyms have been implemented as search keywords.

\section{Database preparation}

VueJS, (https://vuejs.org/) a Javascript framework has been implemented for building the frontend of MPDB 2.0. ElasticSearch, (https://www.elastic.co/) a distributed storage and analytics engine has been utilized as the backend of this database. For ensuring the robustness of search functionality Edge-ngram tokenizer has been employed alongside ElasticSearch's standard tokenizer when indexing the documents. FastAPI, (https://fastapi. tiangolo.com/) a Python web framework has been utilized in building the middleware for this database which 


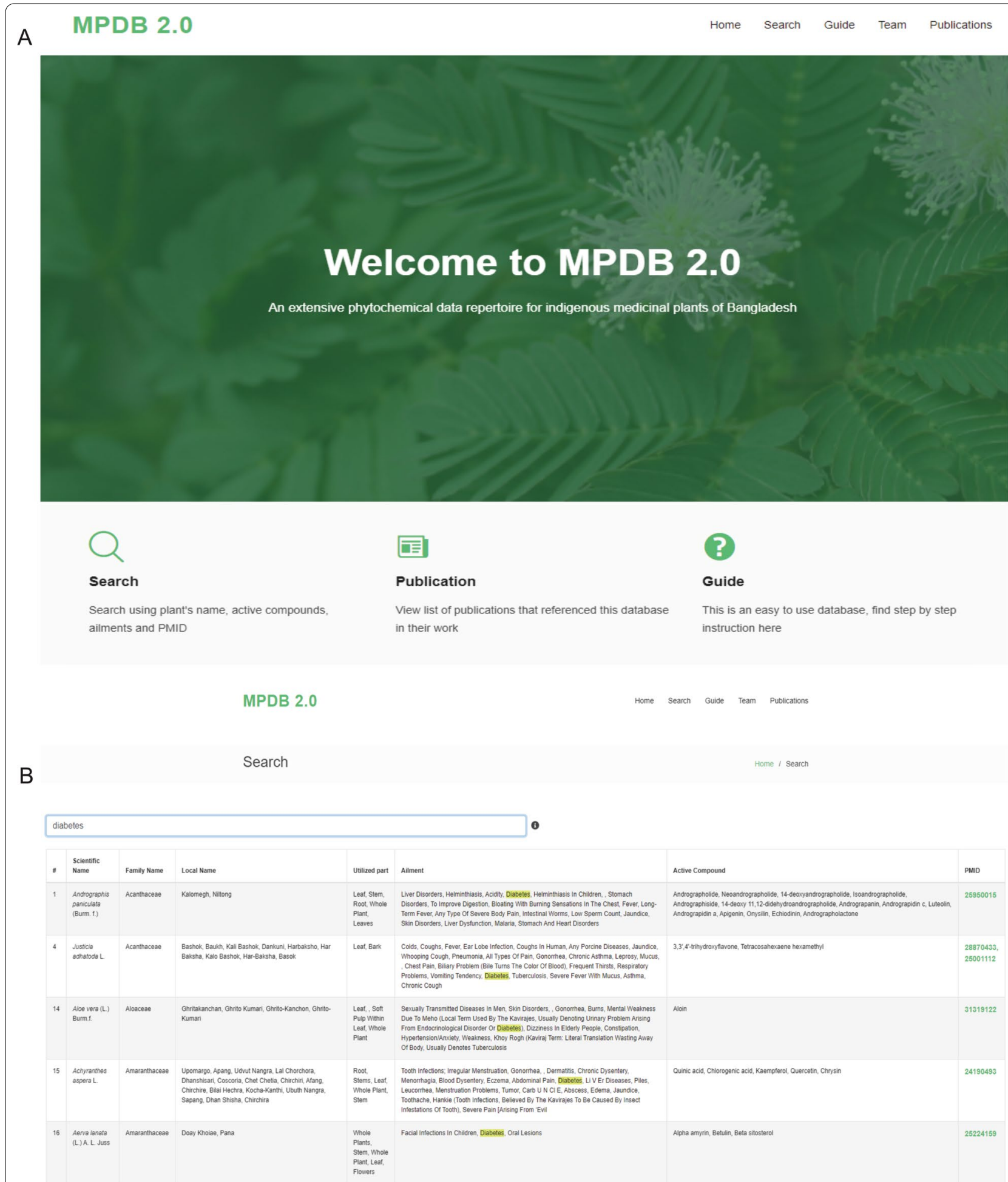

Fig. 3 A Interface of MPDB2.0 database. B Keyword search result demonstrates related plant, their scientific names, source of plant, utilized parts, ailment, available active compounds, source of article, and hyperlinked PubMed ID of the reference papers 
translates the request-response between frontend and ElasticSearch.

\section{Database access}

The MPDB 2.0 database contains five pages among which the "Search" (Fig. 3) page displays and gives access to the indexed Bangladeshi medicinal plants information along with their active compounds list. The search functionality within this page enables a user to query the database using one or more keywords (scientific name, local name, utilized parts, ailments, active compounds, and PMID) for normal or Boolean search. Every keyword entered is attempted to match with all the fields unless the field is specified. Several singles keyword queries matched with different fields are illustrated in Fig. 3. Users can search by stitching the keywords with AND/OR operator. Some plant entries contain multiple PMID entries as when collecting active compounds data, the authors used multiple references, in such cases clicking on the PMID section allows the users to see which active compounds belong to which publications, improving the overall user-friendliness of the database (Fig. 3).

\section{Conclusion}

MPDB 2.0 is the continuation of MPDB 1.0, while it is established upon the same initial structure as MPDB 1.0 , it contains a much larger data repository compared to its predecessor and the released version is much more refined and user friendly than MPDB 1.0. The MPDB 2.0 database has been dedicated to being a promising webserver engine for the initial screening of phytochemicals in silico drug development.

\section{Limitations}

In order to reduce over-complexity, when some plants had multiple publications describing different active compounds composition, only the publication with the highest number of validated active compounds have been indexed in the database, which reduces the possible data density of the database. Also, the plant information indexed in MPDB 2.0 with the exceptions of active compounds and PubMed IDs have been collected from publications on Bangladeshi medicinal plants, since there has been a server lack of wet lab works on these Bangladeshi plants in Bangladesh, and their metabolite composition has not been evaluated locally. A separate literature mining was conducted to identify the active compounds of these plant species from publications and research works of other countries. Since the geodemographic distribution of plants has a considerable effect on the composition of their metabolites, the accuracy of the active compounds listed in the database remains open to questions. The authors hope to remove these inadequacies in future editions of the MPDB.

\section{Abbreviations}

MPDB 2.0: Medicinal plant database 2.0; PMID: PubMed unique identifier.

\section{Acknowledgements}

The authors would like to thank researchers around the globe for their relentless effort to put together the information on medicinal plants.

\section{Authors' contributions}

$\mathrm{NH}$ and RC prepared the background material for the database. RAA, MAM, and MKH supervised and coordinated the project. MAA adopted the idea and coordinated the database project. All the authors involved in this project participate in writing and editing the final version of the manuscript. All authors read and approved the final manuscript

Funding

This project is currently not funded.

\section{Availability of data and materials}

Data used in this study or produced is either available from the public domain or mentioned here in the manuscript. Apart from that, authors always welcome to share the data required for reviewers and other researchers.

\section{Declarations}

Ethics approval and consent to participate Not applicable.

\section{Consent for publication}

Not applicable.

\section{Competing interests}

Authors declare no competing interests.

\section{Author details}

${ }^{1}$ Department of Biochemistry and Molecular Biology, Tejgaon College, National University of Bangladesh, Gazipur 1704, Bangladesh. ${ }^{2}$ Bio-Bio-1 Bioinformatics Research Foundation, Dhaka, Bangladesh. ${ }^{3}$ Shahjalal University of Science and Technology, Sylhet, Bangladesh. ${ }^{4}$ Biology department, University of Massachusetts Amherst, Amherst, MA, USA.

Received: 5 April 2021 Accepted: 29 July 2021

Published online: 06 August 2021

\section{References}

1. Ashraf MA. Phytochemicals as potential anticancer drugs: time to ponder nature's bounty. Biomed Res Int. 2020;2020:1-7.

2. Ong HG, Kim YD. Medicinal plants for gastrointestinal diseases among the Kuki-Chin ethnolinguistic groups across Bangladesh, India, and Myanmar: a comparative and network analysis study. J Ethnopharmacol. 2020;251:112415

3. Asadi-Samani M, Kafash-Farkhad N, Azimi N, Fasihi A, Alinia-Ahandani E, Rafieian-Kopaei M. Medicinal plants with hepatoprotective activity in Iranian folk medicine. Asian Pac J Trop Biomed. 2015;5:146-57.

4. Martins N, Ferreira ICFR, Barros L, Carvalho AM, Henriques M, Silva S. Plants used in folk medicine: the potential of their hydromethanolic extracts against Candida species. Ind Crops Prod. 2015;66:62-7.

5. Ma X, Meng Y, Wang P, Tang Z, Wang H, Xie T. Bioinformatics-assisted, integrated omics studies on medicinal plants. Brief Bioinform. 2020:21:1857-74

6. De Silva AM, Manville RW, Abbott GW. Deconstruction of an African folk medicine uncovers a novel molecular strategy for therapeutic potassium channel activation. Sci Adv. 2018;4:eaav024. 
7. Wangkheirakpam S. Traditional and folk medicine as a target for drug discovery. In: Natural products and drug discovery: an integrated approach; 2018. pp. 29-56.

8. Hassannia B, Logie E, Vandenabeele P, Berghe TV, Berghe WV. Withaferin A: from ayurvedic folk medicine to preclinical anti-cancer drug. Biochem Pharmacol. 2020;173:113602.

9. McChesney JD, Venkataraman SK, Henri JT. Plant natural products: back to the future or into extinction? Phytochemistry. 2007;68:2015-22.

10. Goossens A, Häkkinen ST, Laakso I, Seppänen-Laakso T, Biondi S, De Sutter $\mathrm{V}$, et al. A functional genomics approach toward the understanding of secondary metabolism in plant cells. Proc Natl Acad Sci U S A. 2003;100:8595-600.

11. Birari RB, Bhutani KK. Pancreatic lipase inhibitors from natural sources: unexplored potential. Drug Discov Today. 2007;12:879-89.

12. Chartrain M, Salmon PM, Robinson DK, Buckland BC. Metabolic engineering and directed evolution for the production of pharmaceuticals. Curr Opin Biotechnol. 2000;11:209-14.

13. Wang Y, Fan $C$, Hu H, Li Y, Sun D, Wang Y, et al. Genetic modification of plant cell walls to enhance biomass yield and biofuel production in bioenergy crops. Biotechnol Adv. 2016:34:997-1017.

14. Jamshidi-Kia F, Lorigooini Z, Amini-Khoei H. Medicinal plants: past history and future perspective. J HerbMed Pharmacol. 2018;7:1-7.
15. Li JWH, Vederas JC. Drug discovery and natural products: end of an era or an endless frontier? Science. 2009;325:161-5.

16. Ak M. A brief review of traditional plants as sources of pharmacological interests. Open J Plant Sci. 2019;4(1):001-8.

17. Rahal-Bouziane $H$. The powerful healing effect of traditional medicine for the treatment of certain chronic diseases: one of the means to better defeat Covid-19. J Basic Appl Res Biomed. 2020;6:106-13.

18. Rakib A, Paul A, Nazim Uddin Chy M, Sami SA, Baral SK, Majumder M, et al. Biochemical and computational approach of selected phytocompounds from Tinospora crispa in the management of COVID-19. Molecules. 2020;25(17):3936.

19. Ashraf MA, Khatun A, Sharmin T, Mobin F, Tanu AR, Morshed T, et al. MPDB 1.0: a medicinal plant database of Bangladesh. Bioinformation. 2014:10:384-6.

\section{Publisher's Note}

Springer Nature remains neutral with regard to jurisdictional claims in published maps and institutional affiliations.
Ready to submit your research? Choose BMC and benefit from:

- fast, convenient online submission

- thorough peer review by experienced researchers in your field

- rapid publication on acceptance

- support for research data, including large and complex data types

- gold Open Access which fosters wider collaboration and increased citations

- maximum visibility for your research: over 100M website views per year

At BMC, research is always in progress.

Learn more biomedcentral.com/submissions 